IZA DP No. 741

Wages, Sorting on Skill, and the

Racial Composition of J obs

Barry T. Hirsch

David A. Macpherson

March 2003 


\title{
Wages, Sorting on Skill, and the Racial Composition of Jobs
}

\author{
Barry T. Hirsch \\ Trinity University and IZA Bonn
}

David A. Macpherson

Florida State University

\author{
Discussion Paper No. 741 \\ March 2003
}

\author{
IZA \\ P.O. Box 7240 \\ D-53072 Bonn \\ Germany \\ Tel.: +49-228-3894-0 \\ Fax: +49-228-3894-210 \\ Email: iza@iza.org
}

This Discussion Paper is issued within the framework of IZA's research area The Future of Labor. Any opinions expressed here are those of the author(s) and not those of the institute. Research disseminated by IZA may include views on policy, but the institute itself takes no institutional policy positions.

The Institute for the Study of Labor (IZA) in Bonn is a local and virtual international research center and a place of communication between science, politics and business. IZA is an independent, nonprofit limited liability company (Gesellschaft mit beschränkter Haftung) supported by the Deutsche Post AG. The center is associated with the University of Bonn and offers a stimulating research environment through its research networks, research support, and visitors and doctoral programs. IZA engages in (i) original and internationally competitive research in all fields of labor economics, (ii) development of policy concepts, and (iii) dissemination of research results and concepts to the interested public. The current research program deals with (1) mobility and flexibility of labor, (2) internationalization of labor markets, (3) welfare state and labor market, (4) labor markets in transition countries, (5) the future of labor, (6) evaluation of labor market policies and projects and (7) general labor economics.

IZA Discussion Papers often represent preliminary work and are circulated to encourage discussion. Citation of such a paper should account for its provisional character. A revised version may be available on the IZA website (www.iza.org) or directly from the author. 


\section{ABSTRACT}

\section{Wages, Sorting on Skill, and the Racial Composition of Jobs*}

Wages for black and white workers are substantially lower in occupations with a high density of black employees, following standard controls. Such correlations can exist absent discrimination or as a result of discrimination. In wage level equations, the magnitude of the correlation falls sharply after controlling for occupational skills. Longitudinal estimates accounting for worker heterogeneity indicate little if any wage change associated with changes in racial composition. Results support a "quality sorting" explanation, with racial density serving as an index of unmeasured skills. Although past discrimination helps determine the present pattern of job sorting, current discrimination cannot explain the relationship between wages and racial density. Current discrimination reflected in racial wage gaps occurs within occupations or across occupations in a manner uncorrelated with racial composition.

JEL Classification: J3, J7

Keywords: discrimination, racial composition, skill sorting

Corresponding author:

Barry T. Hirsch

Department of Economics

Trinity University

San Antonio, TX 78212

USA

Tel.: +1 8506443586

Fax: +1 8506444535

Email: bhirsch@trinity.edu

\footnotetext{
* Helpful comments were received on an early version of this research from Maria Cancian, Darren Grant, Robert Hauser, William Johnson, Maurice MacDonald, Derek Neal, Edward Schumacher, Eric Solberg, Andrew Weiss, and seminar participants at several universities. The Institute for Research on Poverty, University of Wisconsin, Small Grants Program provided financial assistance. The current version benefited from the suggestions of the Editor and an anonymous referee.
} 


\section{Introduction}

Estimation of racial wage gaps has been a focus of much research by economists (Altonji and Blank 1999). Little attention, however, has been devoted to the question of why wages of black and white workers are far lower in occupations with high concentrations of African-Americans. ${ }^{1}$ Although this relationship can exist absent current labor market discrimination, a common interpretation has been that it reflects systematic discrimination in access to jobs. Darity and Mason (1998), for example, interpret racial segregation as the outcome of profit-enhancing employer discrimination intended to hold down bargaining power and wages. "This approach emphasizes that the major elements for the persistence of discrimination are racial or gender differences in the access to better paying jobs within and between occupations" (Darity and Mason 1998, pp. 86-87). Mason (1999) argues that "job competition" theory, whereby minorities face discriminatory barriers to good jobs, accounts for a sizable share of the racial wage gap. This conclusion is based in large part on the finding that wages for all workers are higher in jobs with higher proportions of white males.

Hirsch and Schumacher (1992) find that wages for white and black workers are significantly lower in industry-occupation-region groups with a high proportion of black workers. They argue, however, that the specific pattern of results found are not readily explained by standard statistical discrimination models, the crowding hypothesis, or taste theories of discrimination. They propose what they refer to as a "quality sorting" explanation. A quality sorting equilibrium implies that the proportion of black workers in a job is correlated with measured and unmeasured labor productivity differences. Higher skill black and white workers are sorted into jobs with relatively small proportions of black workers, and vice-versa. Wages vary with the racial density of jobs, but density need not be a causal determinant of individual wages. Although their findings are consistent with the quality sorting explanation, the authors provide no direct evidence.

This paper extends the Hirsch-Schumacher analysis, examining in detail the relationship between wages and racial composition. Wage level equations augmented by job characteristics and longitudinal analysis permit us to distinguish between alternative explanations. We conclude that the racial composition of occupations is an important and typically neglected correlate of wages, but that its causal effect is

\footnotetext{
${ }^{1}$ Similar relationships hold with respect to gender and Hispanic densities. Studies of wages and gender composition include Sorensen (1989), Macpherson and Hirsch (1995), and Baker and Fortin (2001). The relationship between wages and racial and/or ethnic composition is the principal focus of papers by Hirsch and Schumacher (1992), Mason (1999), and Bayard et al. (1999). Bayard et al. (1999) find that establishment-level racial and ethnic composition are important wage determinants and conclude that greater segregation between black and white men than women accounts for a sizable share of the higher black-white wage gap among men than women.
} 
minimal. Rather, racial density serves primarily as an index of otherwise unmeasured occupational skills and individual worker heterogeneity. Historical discrimination seems certain to have heavily influenced the sorting equilibrium observed in today's labor market. Indeed, any factor that produces an average skill difference between demographic groups is likely to result in a partial correlation between individual wages and a group's occupational density, assuming that some skills are unmeasured.

Section II of the paper describes how the demographic composition of a job can serve as a proxy for unmeasured skill when there is sorting on labor quality. Section III outlines the empirical strategy intended to distinguish between quality sorting and job discrimination, describes data sources, and presents descriptive evidence. Estimation results from wage level and change equations are presented in Section IV. Section $\mathrm{V}$ considers the role of gender and ethnic segregation. A brief concluding section follows.

\section{Wages and Racial Composition: A Simple Model with Quality Sorting}

The racial composition of jobs may serve as a proxy for unmeasured worker and job skills in labor markets with or without discrimination. A negative correlation between wages and the proportion of black workers can exist absent current discrimination, following typical controls. This outcome follows if: a) the proportion of white workers with high skills exceeds that of black workers; b) some skills observable to employers are unmeasured by researchers; and c) the matching of workers and jobs is based on skill.

The first requirement can result from past labor market discrimination and past or present "societal" discrimination, resulting in lower premarket skills among African Americans. For example, differences in resources and school quality result in subsequent performance differences in the labor market (for a range of evidence, see Card and Krueger 1992; Boozer et al. 1992; and Grogger 1996). The second requirement is that workers receive compensation based not only on skills measured by the researcher, but also unmeasured skills observable to employers. The third requirement - sorting by skill - is discussed subsequently.

A simple identity illustrates the key points. Workers are either high or low quality, and their marginal revenue products are represented by $H$ or $L$. Let $P_{b}$ and $P_{w}$ represent the proportions of black and white workers with productivity $H$, and $\left(1-P_{b}\right)$ and $\left(1-P_{w}\right)$ the proportions with productivity $L$. Assume initially that individual productivities are independent of the place of work. The average productivities or wages of black and white workers, $V_{b}$ and $V_{w}$ respectively, are:

$$
V_{b}=P_{b} H+\left(1-P_{b}\right) L
$$




$$
V_{w}=P_{w} H+\left(1-P_{w}\right) L
$$

Let racial composition be measured by the proportion of black workers in a job $(B)$. The average productivity and wage across workplaces:

$$
V=B V_{b}+(1-B) V_{w}=B\left[P_{b} H+\left(1-P_{b}\right) L\right]+(1-B)\left[P_{w} H+\left(1-P_{w}\right) L\right] .
$$

Taking the derivative of $\mathrm{V}$ with respect to $B$ shows how workplace wages vary with $B$,

$$
\partial V / \partial B=\left(P_{b}-P_{w}\right)(H-L)
$$

If $P_{w}>P_{b}$, the average wage decreases with respect to $B$. The relationship is stronger the larger the racial gap in $P$ and the larger the skill difference between $H$ and $L$ workers.

The assumption $P_{w}>P_{b}$ is sufficient to produce a negative correlation between wages and the racial density of jobs, absent control for measurable characteristics. But regression analysis with controls would eliminate such a correlation if all observable skills are measured, or if unmeasured skills are uncorrelated with race. Even if unmeasured skills are correlated with race, a regression including a binary race variable is likely to largely capture the correlation between wages and $B$.

A relationship between wages and racial composition arises when there is sorting by skill. We refer to this as quality sorting, by which we mean that $P_{b}$ and $P_{w}$ increase across jobs as skill requirements increase, and vice-versa. An employer who can observe worker productivity and chooses to hire a high skill workforce (due, say, to the firm's technology) selects a lower proportion of black workers than in the average workplace (since $P_{w}>P_{b}$ ) and a higher than average proportion of $H$ quality black and white workers. Black and white wages decrease with respect to $B$, since $B$ reflects selective hiring (i.e., a higher proportion of $H$ quality workers as $B$ decreases), but $B$ has no causal effect on wages.

The quality sorting model described above would account for the negative correlation between wages and $B$ found in wage level equations, since $B$ serves as a skill index for white and black workers. It would not be consistent with correlation in a longitudinal framework. Following job changes, $\Delta W$ should be uncorrelated with $\Delta B$ if workers are paid based on observed productivity. The absence of a relationship between $\Delta W$ and $\Delta B$ is inconsistent with a job discrimination explanation.

Alternative variants of quality sorting permit a negative relationship of wages with $B$ both in wage level and change equations. Rather than assuming that productivity $H$ and $L$ are fixed across jobs, let an individual's productivity vary with mean productivity at the job, increasing as $B$ decreases. If productivity 
and wages are determined by workers and the job, a negative relationship between $W$ and $B$ results in both wage level and change equations. A finding of no relationship between $\Delta W$ and $\Delta B$ provides evidence inconsistent with discriminatory job competition, but a negative relationship is consistent with either discrimination or the more complex process of wage determination described above. ${ }^{2}$

Although the absence of a relationship between $\Delta W$ and $\Delta B$ would allow rejection of the job competition explanation, it would not rule out all forms of racial discrimination. Current labor market discrimination might fail to explain the relationship between wages and racial composition, but could occur within occupations (jobs) or across occupations (jobs) in ways uncorrelated with $B$.

\section{Wages and Racial Composition: Specification, Data, and Descriptive Evidence}

\section{A. Empirical Specification and Strategy}

The relationship between wages and racial composition is examined through the estimation of wage level and change equations. Our basic strategy is straightforward. If $B$ serves as an index of skill, then the absolute value of its coefficient should decline as measured skill variables are introduced into wage level equations. Occupational skill variables (e.g., computer use) not only measure job skills directly, but also capture unmeasured worker skills on which sorting takes place. ${ }^{3}$ Longitudinal analysis allows a test of whether black and white workers realize penalties and gains when moving into occupations with higher and lower proportions of black workers. The absence of a correlation between $\Delta W$ and $\Delta B$ would support models wherein workers are paid their marginal products, independent of the racial composition of jobs, while being inconsistent with the discriminatory job competition hypothesis.

Specifically, the relationship between wages and racial composition is estimated in levels by:

$$
\begin{aligned}
& \ln W_{i t b}=\Sigma \beta_{k b} X_{i k t b}+\Sigma \psi_{j b} Z_{i j t b}+\theta_{b} \ln B_{i t b}+\Phi_{i b}+\varepsilon_{i t b}, \\
& \ln W_{i t w}=\Sigma \beta_{k w} X_{i k t w}+\Sigma \psi_{j w} Z_{i j t w}+\theta_{w} \ln B_{i t w}+\Phi_{i w}+\varepsilon_{i t w} .
\end{aligned}
$$

Subscripts $b$ and $w$ designate black and white, $\ln W_{i t}$ is the natural $\log$ of hourly earnings for individual $i$ in year $t ; X_{k}$ consists of $X_{l}=1$ and $k-1$ variables measuring personal or locational characteristics measured at the individual level; $\beta_{k}$ includes a constant and $k-1$ coefficients corresponding to variables in $X ; Z_{j}$ consists of $j$ variables measuring occupational skills and working conditions (including occupation means of the $X$ 's)

\footnotetext{
${ }^{2}$ Models of mobility and job shopping (e.g., Johnson 1978; Jovanovic 1979) suggest that voluntary job changes are associated with better matches between workers and jobs (leading to wage gains), and that productivity of heterogeneous workers may become better known to employers over time (leading to faster wage growth).
} 
with $\psi_{j}$ being the corresponding coefficients; $\ln B$ is the natural $\log$ of the proportion of black to total employment in the worker's detailed occupation (use of $\ln B$ rather than $B$ is discussed subsequently); $\theta$ is the coefficient on $\ln B$ representing an elasticity of wages with respect to $B ; \Phi_{i}$ is a worker fixed effect (invariant over one year in most of our models); and $\varepsilon$ is an error term. ${ }^{4}$

If the omitted fixed effect $\Phi_{i}$ is negatively correlated with $B$, then levels estimates of $\theta_{w}$ and $\theta_{b}$ in (5) and (6) are negatively biased (away from zero). Letting $\Delta$ represent changes between adjacent years $[t-(t$ $1)],[(t-1)-(t-2)]$, etc., the following longitudinal wage change equations are obtained:

$$
\begin{aligned}
& \Delta \ln W_{i y b}=\Sigma \beta_{k b} \Delta X_{i k y b}+\Sigma \psi_{j b} \Delta Z_{i j y b}+\theta_{b} \Delta \ln B_{i y b}+\Delta \varepsilon_{i y b}, \\
& \Delta \ln W_{i y w}=\Sigma \beta_{k w} \Delta X_{i k y w}+\Sigma \psi_{j w} \Delta Z_{i j y w}+\theta_{w} \Delta \ln B_{i y w}+\Delta \varepsilon_{i y w},
\end{aligned}
$$

where $y$ represents change periods. Fixed effects owing to worker heterogeneity fall out, potentially allowing unbiased estimates of $\theta_{b}$ and $\theta_{w}$. Econometric issues are addressed subsequently.

\section{B. Data}

Wage equations are estimated using three alternative panel or retrospective data sets. First is the monthly Current Population Survey Outgoing Rotation Group (CPS-ORG) earnings files. Households are included in the CPS in the same month for consecutive years, permitting construction of large panels of adjacent worker-year pairs. We construct a panel for the periods 1991/2 through 1997/8 (276,965 pairs of observations) from which we estimate wage level and change equations. ${ }^{5}$

The second data source is the 1992-98 March CPS Annual Demographic files ( $n=98,759)$, which contain information on the longest job last year and the current job, the latter obtained from matched MarchJune ORG records. Wage equations are also estimated from a third data source - the eight biennial CPS Displaced Worker Surveys (DWS) during 1984-98. The DWS provide current and retrospective job

\footnotetext{
${ }^{3}$ Pierce (2000) concludes that job content variables measured at the occupation-by-establishment level appear to reflect worker ability. He does not have data on individual characteristics.

${ }^{4}$ Matching grouped (occupation) data to individual observations biases downward standard errors, but need not bias coefficient estimates (Moulton 1990). Estimates of $\theta_{b}$ and $\theta_{w}$ may be biased if $B$ is correlated with occupationlevel wage determinants not included in the earnings equations. In their analysis of wages and gender composition, Baker and Fortin (2001) recommend inclusion not only of $X_{i}$ measured at the individual level, but also the means of $X_{i}$ at the occupation level in order to control for omitted occupational wage determinants. We follow this advice.

${ }^{5}$ Beginning in 1994, the CPS includes individual as well as household identifiers, making panel construction straightforward (validity checks are used as well). For years prior to 1994, construction is more involved (Macpherson and Hirsch 1995). Exclusion from the ORG panel results if a household moves, if an individual leaves a household, if the Census is unable to reinterview a household, if a worker becomes self employed, and if an individual drops out of the labor market. Wage level and change estimates of $\theta$ for 1992-98 are moderately larger in magnitude than those based on earlier periods. Estimates by year for 1973 forward indicate a strengthening relationship between wages and
} 
information for workers who have had permanent layoffs within the past five years (for surveys through 1992) or three years (beginning 1994), resulting in a total sample of 15,570 job switchers. Advantages and disadvantages of these data are discussed in Section IV. We match to each individual record in the three CPS datasets variables measuring job characteristics. These are either calculated by us from the CPS-ORG files or special CPS supplements, or obtained from the Dictionary of Occupational Titles (DOT). ${ }^{6}$

Included in the analysis are black and white wage and salary workers ages 16 and over. Excluded are workers not white or black, full-time students, individuals with occupation or industry allocated by the Census (about 1 percent of the sample), and a very small number for whom hourly earnings could not be computed. Wage rates in the ORG files are measured by usual weekly earnings, inclusive of tips, commissions, and overtime, divided by usual hours worked per week, in 1998 dollars. In order to remove outliers owing to reporting error, we exclude workers with measured wages less than $\$ 1.00$ or greater than \$99.99 in 1998 dollars. Nominal weekly earnings are top-coded at \$1,923 through 1997 and \$2,885 in 1998 . Top-coded values are assigned the estimated mean above the cap based on the assumption that the upper tail of earnings follows a Pareto distribution. Estimates of means by gender for years since 1973 are shown in Hirsch and Macpherson (2002, p. 6). These values are approximately 1.5 times the cap, with somewhat smaller female than male means and modest growth over time.

\section{Descriptive Evidence}

Racial composition is measured by $B$, the proportion of black workers in the worker's 3-digit Census occupation. It is measured by the ratio of black to total employment by occupation, calculated for all wage and salary workers ages 16 and over, with no additional sample restrictions. Values of $B$ by race/gender group are provided in Table 1 for selected years between 1973-98. Also shown is the Duncan index, defined as $\left|w_{j}-b_{j}\right|$, where $w_{j}$ and $b_{j}$ are the proportions of non-black and black employment in occupation $\mathrm{j}$. It ranges between zero (complete integration) and one (complete segregation). Both measures indicate declining racial segregation, particularly among women. $B$ has increased over the period by about 2 percentage points for white men and women (from roughly 9 to 11 percent for men and 10 to 12 percent for women). $B$ has decreased most significantly for black women, from about 21 to 16 percent, while declining only modestly

racial density, particularly among women. If $B$ serves as a proxy for unmeasured skills, the increase in $\theta$ can be interpreted as resulting from increased skill differentials during the 1980s (see Card and Lemieux 1996). 
among black males. The Duncan segregation index has fallen from .384 to .284 among males and from .374 to .241 among women. ${ }^{7}$ Much of the decline in occupational segregation occurred during the 1970s, with little change in the 1980s and early 1990s, and modest improvements since the early 1990s. In the analysis that follows, $B$ is calculated from the pooled 1992-98 CPS-ORG files and treated as fixed. This is intended to reduce measurement error in $B$ for those (relatively few) workers in small occupational cells.

Table 2 presents the means of wages, schooling, and selected occupational variables. Workers are segmented into three categories based on racial density, with breakpoints for $B$ of .09 and .16 (the pattern of results is invariant to alternative breakpoints). Wages and schooling for black and white workers decrease substantially as $B$ increases. Occupational variables that reflect the level of skill differ systematically with respect to $B$. The proportion of workers receiving formal job training is lowest in high $B$ jobs, computer use falls as $B$ increases, and values of the DOT aptitude requirement measures Numerical, Verbal, and Spatial decline with respect to racial composition. DOT measures of working conditions indicate environmental disamenities (including hazards), physical demands, and strength are greater in high $B$ than in low $B$ occupations. All else equal, differences in job disamenities should lead to equilibrium wages that rise with $B$. The occupational share of Hispanics is highly correlated with $B$, whereas $\%$ Female is weakly related.

\section{Wages and Racial Composition: Empirical Evidence}

\section{A. Wage Level Results}

Table 3 presents the racial composition coefficients from wage level equations, estimated by demographic group, from the alternative data sets. We provide results from two specifications, a "standard" model including a typical set of mostly individual characteristics (vector $X$ ), and an "expanded" model including job characteristics (vector $Z$ ), most of which measure the skill composition or working conditions of the occupation (see the table note for details). The expanded model includes occupational means of most of the $X$ 's in order to purge spurious correlation between $\ln B$ and $X$ (Baker and Fortin 2001). ${ }^{8}$

Racial density is measured by $\ln B$ rather than $B$. This reflects a nonlinear relationship for each of the four groups wherein there is a weaker response of wages to racial density as $B$ increases. A potential

\footnotetext{
${ }^{6}$ The DOT provides information on the content and characteristics of detailed occupations based on evaluations by job analysts. We use the DOT data set and matching process developed by England and Kilbourne (1988), who provide a weighted mapping of 1977 Fourth Edition DOT variables to 1980 Census occupation codes.

${ }^{7}$ Silber (1989) compares the Duncan index to alternative indices of segregation.

${ }^{8}$ We do not include occupational dummies since $B$ is measured at the occupation level and dummies could capture job barriers as well as skills. Estimates of $\theta$ decrease (in absolute value) when dummies are included.
} 
explanation is that increases in $B$ have little effect among low-wage workers whose wages are close to a binding minimum wage. The $W-B$ relationship, however, is found to be nonlinear at wages well above the minimum wage threshold, and remains nonlinear when low-wage workers are excluded from the sample. ${ }^{9}$

Wage levels estimates shown in Table 3 are based on the second year for each worker-year pair 1992-98 for the CPS-ORG and March CPS files, and survey years for the DWS. Despite differences in samples and specification, point estimates of $\theta$ are broadly similar across demographic groups and data sets. A value of $\theta$ close to -.15 indicates that each 10 percent increase in $B$ is associated with $1 \frac{1}{2}$ percent lower wages. A 10 percent increase in $B$ corresponds to changes in $B$ of about 1 and 1.5 percentage points for white and black workers, respectively (see Table 1 means). ${ }^{10}$

We next estimate the "expanded" models. Inclusion of skill and working condition variables sharply reduces (in absolute value) estimates of $\theta_{b}$ and $\theta_{w}{ }^{11}$ Based on the ORG panel, the elasticity of wages with respect to $B$ among men is -.02 for blacks and -.05 for whites; among women -.08 for blacks and -.06 for whites. The substantial reduction in $\theta$ following inclusion of skill-related job measures provides support for the thesis that $B$ serves primarily as a skill index among individuals and jobs. A value of $\theta=-.05$ implies that a $10 \%$ reduction in $B$ increases wages by only one-half a percentage point.

We also examined the sensitivity of estimates of $\theta$ to the choice of controls (Hirsch and Macpherson 2001). The results support the thesis that $B$ serves as an index for worker and job skills. Beginning with just $\ln B$ included, $\theta$ estimates decline sharply when individual controls are added, and then drop roughly in half when broad occupation dummies are included or by more than half if occupational skills and working conditions (but not dummies) are added. Inclusion of the occupation means of $X$ further reduces $\theta{ }^{12}$

\footnotetext{
${ }^{9}$ Our working paper examines the issue of nonlinearity in some detail (Hirsch and Macpherson 2001).

${ }^{10}$ Wage level results using the full CPS rather than the panel sample produces similar results (Hirsch and Macpherson 2001). It is important to estimate separate rather than pooled equations for black and white workers. Even though we obtain similar values of $\theta_{b}$ and $\theta_{w}$, a pooled equation produces a significantly lower $\theta$ (in absolute value) than either $\theta_{b}$ or $\theta_{w}$. This is because the distribution of $B$ differs greatly by race and the pooled $\theta$ is flattened to fit across the distributions. The racial composition effect is found to be statistically driven by nationwide rather than regional differences in $B$, consistent with the thesis that $B$ serves as an occupational skill index.

${ }^{11}$ Complete results for the expanded model are provided in Hirsch and Macpherson (2001). Coefficients on most variables are consistent with expectations, although signs on job characteristics cannot be predicted unambiguously given worker heterogeneity (Hwang, Reed, and Hubbard 1992).

${ }^{12}$ We examined $\theta$ using alternative combinations of the expanded variables. Decline in $\theta$ is most evident following inclusion of OCC-Computer and the DOT aptitude measures. Computer use is likely to proxy non-computer as well as computer skills (DiNardo and Pischke 1997). Differences in $\theta$ across alternative skill groups (not shown) reinforce the quality sorting explanation. A stronger $W$ - $B$ relationship at higher levels of schooling comports well with the finding that black-white ability gaps (measured by AFQT) widen as schooling levels increase (O'Neill 1990). A weaker $W$ - $B$ relationship among young than among older workers is consistent with the narrowing in black-white test
} 
A final issue regarding the wage level results concerns the downward bias in the standard error on the racial composition coefficients associated with matching aggregate data on occupations to individual worker data (Moulton 1990). To provide a benchmark on the potential bias, we used a two-step estimation strategy suggested by Dickens and Ross (1984) and extended by Baker and Fortin (2001) based on the full CPSORG sample (for results, see Hirsch and Macpherson, 2001). As compared to results shown, WLS point estimates of $\theta$ from the second-step standard model are a bit smaller, while those from the expanded model are somewhat larger. For all race/gender groups, standard errors on $\theta$ in the second-step occupation equations are just below .01 in the standard models and just above .01 in the expanded models.

An alternative approach was to estimate the models using a single step random effects model accounting for the repeated observations by occupations. Standard errors on $\theta$ are roughly double those based on OLS estimation. Neither the two-step nor the random effects approach to estimating standard errors can be readily used with respect to the longitudinal estimates, since the aggregate matching now involves occupation pairs over the two time periods. Because repeated observations by occupation pair is limited, standard error bias in the change models may be less than in the level equations.

Our "expanded" cross sectional evidence, while suggestive, does not rule out the possibility that the negative correlation between $W$ and $B$ in the standard model is driven by job discrimination, with many African Americans and few whites relegated to low skill jobs. ${ }^{13}$ By this reasoning $\theta_{b}$ serves as a measure of discrimination, while a negative $\theta_{w}$ (inconsistent with discrimination favoring whites) would reflect sorting on unmeasured skills among whites. If job discrimination is the explanation for a negative $\theta_{b}$, however, longitudinal results for black workers should exhibit significant wage changes associated with changes in $B$.

\section{B. Longitudinal Results}

In order to test whether unmeasured worker skills correlated with racial density account for the relationship between $B$ and wages, longitudinal evidence is examined. We estimate wage change equations using three alternative panel or retrospective data sets, each with advantages and disadvantages. The simple quality sorting hypothesis implies that wage changes among occupation switchers should not be correlated

scores occurring within schools (Cook and Evans 2000). The finding that racial composition tends to have smaller effects in groups where African Americans are over-represented (e.g., less educated, South, young, union, and production workers) argues against discriminatory crowding explanations of the racial composition effect.

${ }^{13}$ Gill (1989) and Filer (1986) examine job barriers by comparing occupational desires and attainment. Gill finds little racial difference in desires, but significant differences in attainment. Filer concludes that the occupational distribution is largely consistent with choice. 
with changes in racial composition. Absence of a relationship between $\Delta W$ and $\Delta B$ would be consistent with quality sorting, but inconsistent with the job discrimination explanation. A significant relationship would be consistent with either the job discrimination hypothesis or a model of the labor market in which productivity and wages depend on group as well as individual productivity.

Econometric problems with longitudinal analysis are potentially serious and warrant discussion. Wage change studies are often plagued by small numbers of switchers for the variable under consideration. The CPS panels developed here provide large sample sizes with many occupational switchers. Because our matched pairs are for adjacent years, we must assume that wage changes associated with the change in $B$ are realized quickly. This implies that fixed effects unmeasured by the researcher are known to the employer and quickly reflected in the wage following a job switch. If anything, the short panel should work against a finding that fixed effects account for wage correlation between $\Delta W$ and $\Delta B$. An advantage of the short panel is that the assumption of constant coefficients over a year is a reasonable one. Problematic is the maintained assumption that changes in racial composition are exogenous. Endogenous job switching need not bias estimates of $\theta$, however, if occupational switching is uncorrelated with changes in racial density. Endogenous switching by workers is addressed through the use of the Displaced Worker Surveys (DWS), where exit is involuntary and occupational change is more nearly exogenous.

A concern in longitudinal analysis is bias in $\theta$ resulting from measurement error in $\Delta \ln B$, with bias toward zero proportional to the ratio of error variance to true variance. Such a concern is important in the ORG matched panels since many persons have occupation misclassified (Mellow and Sider 1983) and the time period of the panels is short, leading to a high noise to signal ratio. ${ }^{14}$ Bias associated with mismeasured occupational change is addressed in several ways. The principal way in which we reduce error in the ORG panels is by separating occupational switchers who do and do not report a change in industry. The ORG panel results in Table 3 provide coefficient estimates on $\ln B$ for workers who switch both occupation and industry; separate racial composition coefficients are estimated for those who change occupation but not industry (these are not shown) and dummies are included for switches in industry and occupation, occupation only, and industry only (these coefficients are close to zero and do not affect results). Workers who report changes both in industry and occupation are far more likely to be true occupational changers than

${ }^{14}$ Serial correlation in response error may attenuate bias (for earnings evidence, see Bound and Krueger 1991). We exclude worker-year pairs where occupation or industry has been allocated by the Census in either year. 
workers reporting a different occupation but the same industry. As expected, estimates of $\theta$ for occupationonly switchers are closer to zero than are estimates for occupation and industry switchers. ${ }^{15}$

Although our principal analysis is based on the large CPS-ORG panels, evidence from the March CPS files for 1992-98 and the biennial CPS-DWS surveys for 1984-98 provide measures of $\Delta \ln B$ less affected by error from mismeasured occupational change. The ORG panels rely on information from two interviews, one year apart, conducted by different individuals and possibly with different household members, and coded by different Census coders. The March files, by contrast, rely on information from a single interview with a single household member by a single interviewer and with a single occupation coder (except in the event of an occupation change). ${ }^{16}$ The March files also include workers who have changed households or location, resulting in a more representative sample than the ORG panels. The disadvantages of the March files are that sample sizes are smaller; the wage rate in the previous year is calculated from earnings, weeks, and hours information that may be determined in part by jobs other than the longest held (this produces a modest bias toward zero in estimates based on occupational change, as shown in Macpherson and Hirsch, 1995, p. 458); and information is not available to construct changes in individual union and marital status (these are controlled at the aggregate level).

The CPS-DWS files provide information on whether workers have lost or left a job during the past five years (for 1984-92) or three years (beginning 1994) because of a plant closing, an employer going out of business, a layoff from which a worker was not recalled, or other similar reason. As with the March surveys, it is relatively unlikely that there will be a false identification of switchers in the DWS. In addition, job change among displaced workers is more likely to be exogenous (Gibbons and Katz 1992). The population of displaced workers is unlikely to be fully representative of the larger population. Because wage level estimates using the DWS are similar to those obtained with the ORG and March CPS, we have greater confidence that the longitudinal results will provide reliable estimates of $\theta$. DWS sample sizes are smaller than in the other two data sets, but the DWS includes only job changers.

The longitudinal results establish the importance of worker heterogeneity. Wage change estimates of $\theta$ using the standard specification are substantially smaller than are level estimates. Focusing on the ORG panel, movement from the standard wage level to the change equation causes $\theta$ to fall to a third of its initial

${ }^{15}$ A similar approach is followed in Macpherson and Hirsch (1995), who provide direct evidence showing that most "true" occupational switchers also switch industry. 
value, from about -.17 to between -.04 and -.06. Moving to the expanded model, $\theta$ falls to about -.02 for black and white men and to -.01 for women. Even were such coefficients statistically significant, their magnitude indicates modest wage change associated with changes in racial composition. If $\theta=-.05$ (as in the ORG standard models), a "typical" job switcher $(\Delta \ln B \approx .50)$ realizes a $2 \frac{1}{2} 2$ percent wage change. ${ }^{17}$

The March CPS retrospective data permit inclusion of those changing household or region and measure occupational change more accurately than does the ORG. The levels and change results are broadly similar to those obtained with the ORG. The DWS results, which may be most likely to reflect the long-run effects of job change, indicate values of $\theta$ in the standard specification (for all except white females) that are somewhat smaller than those from the ORG and March CPS. Results using the expanded specification provide no evidence of a relationship between changes in earnings and racial composition.

The clear conclusion from the results in Table 3 is that the strong relationship between the wages of white and black workers and the proportion of black workers in an occupation is accounted for almost entirely by measured and unmeasured worker and job skills. Following control for job skills or accounting for worker heterogeneity, little evidence of an effect of racial composition on wages remains. Racial-based job discrimination is not the driving force behind the strong negative correlation between wages and racial density. Inclusion of $B$ as a control in wage equations can be justified on the grounds that it is a proxy for otherwise unmeasured worker and job skills. Differences in $B$ should not be regarded as a causal determinant of wages or included in the discriminatory component of racial wage gap decompositions.

\section{The Wage Effects of Ethnic and Gender Composition}

This paper has attempted to explain the strong relationship between wages and the racial composition of occupations. The empirical strategy has been to supplement standard wage equations with variables measuring job skill requirements and working conditions and to use longitudinal analysis to account for worker heterogeneity. This strategy appears to be a fruitful approach for understanding why wages are correlated with the demographic composition of jobs. Below, we briefly discuss our results linking wages

${ }^{16}$ We thank Jay Stewart for information about occupational coding.

${ }^{17}$ The mean (median) of $|\Delta \ln B|$ in the ORG panel is .497 (.401) and interquartile range .529. The sample mean (median) of $|\Delta \ln W|$ is .313 (.197). If workers who are part-time in either year are excluded, results shown in Table 3 are affected little. Wage change results are not driven by new entrants or workers switching into and out of part-time jobs. We also estimate the ORG wage level equations with only occupation-industry switchers, since they determine the longitudinal results. Estimates of $\theta$ tend to be a bit lower than those shown (white males are an exception). This is consistent with quality sorting, since those who voluntarily moved are likely to be observed with higher than average wages in high $B$ jobs and lower than average wages in low $B$ jobs. 
with the gender and ethnic composition of occupations.

Results on ethnic composition (available on request) look very much like the results shown for racial composition. All models estimated in this paper include the variable \%Hispanic. For all three data sets and the four race-gender groups, coefficients on \%Hispanic in the standard level equations are negative and large (roughly -1.5 to -2.0 ). These coefficients fall sharply in magnitude when we move from the standard to expanded model. In all cases, estimates from the standard specification drop sharply when we move from a level to change equation. When we restrict the samples to Hispanics, we obtain similar results. In short, \%Hispanic is a strong wage correlate that primarily reflects otherwise unmeasured worker and job skills.

Macpherson and Hirsch (1995) and Baker and Fortin $(1999,2001)$ have used a similar approach to examine the wage effects of gender composition. Our general results here, based on coefficients on the $\%$ Female control variable, comport well with the Macpherson and Hirsch results for the U.S. ${ }^{18}$ Much of the relationship between wages and gender composition can be accounted for by occupational differences and worker heterogeneity. But not all. Particularly among women, there remains a small negative relationship between wages and gender composition, consistent with the existence of occupational crowding owing to discrimination and/or choice. Whereas racial and Hispanic composition serve primarily as indices of unmeasured skills, this is far less true of gender. To the extent that \%Female reflects skills, it is those measured by job training requirements, experience, and part-time and shift work, all related to gender differences in labor supply (factors considered explicitly in Macpherson and Hirsch). The crowding explanation for gender wage differences has plausibility given the size of the female labor force and the family division of labor. The crowding explanation applied to racial or ethnic composition is less plausible ex ante, and inconsistent with our empirical results.

\section{Conclusions}

This study provides evidence on what has been given little attention in the literature - wages for white and black workers vary systematically with the racial composition of jobs. The paper provides support for a quality sorting explanation. The effect of occupational segregation by race is reduced sharply when measures of job skills are introduced into wage level equations. Longitudinal analysis accounting for

\footnotetext{
${ }^{18}$ The exception is that we obtain far smaller coefficients on \%Female among males in our standard equations. The reason is that occupation dummies are excluded here, but are included in Macpherson and Hirsch. Sensitivity of results to inclusion of occupation and industry dummies is shown in Macpherson and Hirsch (1995, Table 5). In
} 
person-specific skills indicates at most a weak relationship between racial composition and wages. Workers switching into or out of occupations realize little wage change associated with changes in racial density.

An implication from our study is that $B$ provides a control for what are typically unmeasured worker quality and job skill differences. It need not follow, however, that racial density explains a large portion of the racial wage gap. We compile estimates of racial log wage gaps for men and women over the 1992-98 period, measured simply by the coefficient on a black dummy variable. The unadjusted racial wage gap for men is .24 and for women $.10 \log$ points. Adding a set of individual controls (but not occupation dummies), the male gap is .18 absent $\ln B$ and .13 with $\ln B$. With the inclusion of 12 occupational dummies, however, the estimated gaps are .14 absent $\ln B$ and .12 with $\ln B$ (corresponding figures for women are .064 and .048). Based on typical specifications of the wage equation including occupation dummies, racial wage gaps are reduced just .01-.02 log points by addition of $\ln B$. The remaining black-white gap is driven largely by wage differences within occupations and by differentials across occupations uncorrelated with racial density. Although we have argued that $B$ is an appropriate control for skill, its absence results in what is a rather modest upward bias to standard measures of the racial gap. ${ }^{19}$

Results in this paper are not without policy implications. If differences in worker skills are a driving force behind current racial employment and wage differentials, the results provide support for strong efforts at enhancing training for African-Americans, both in and out of school. ${ }^{20}$ Such a policy emphasis has particular urgency given demand and supply shifts during the 1980s that favored young workers in skillintensive occupations and produced an increased return to skill (Card and Lemieux 2001). If our quality sorting explanation is valid, then a narrowing of black-white differences in skill will be necessary to weaken what is now a strong negative correlation between wages and the racial composition of jobs.

contrast to U.S. results, the underlying relationship between wages and gender composition in Canada appears to be weak and statistically fragile (Baker and Fortin 1999, 2001).

${ }^{19}$ Remarkably, control for only $\ln B$ produces racial gap estimates not very different from fully-specified models, .13 for men and .02 for women. When gaps are calculated based on separate black and white wage equations, results are similar to those summarized. Our analysis applies strictly only to occupational segregation. There is substantial segregation at the establishment level, but it would be sizable even were employment determined randomly (Carrington and Troske 1998). Bayard et al. (1999) conclude that establishment-level racial segregation accounts in part for the larger racial gap for men than for women. An implication of our results is that the wage-segregation relationship they observe is likely to reflect in no small part unmeasured worker and job skills, and should not be treated as causal.

${ }^{20}$ Existing literature provides evidence that skill differences help account for racial differences in employment (Rivera-Batiz 1992), wages (O'Neill 1990; Neal and Johnson 1996), and wage change (Card and Lemieux 1996). 


\section{References}

Altonji, Joseph G., and Blank, Rebecca M. "Race and Gender in the Labor Market.” In Handbook of Labor Economics, Volume 3C, edited by Orley Ashenfelter and David Card, pp. 3143-259. Amsterdam: North-Holland, 1999.

Baker, Michael, and Fortin, Nicole M. "Women's Wages in Women's Work: A U.S./Canada Comparison of the Roles of Unions and 'Public Goods' Sector Jobs." American Economic Review Papers and Proceedings 89 (May 1999): 198-203.

. "Occupational Gender Composition and Wages in Canada: 1987-1988." Canadian Journal of Economics 34 (May 2001): 345-76.

Bayard, Kimberly; Hellerstein, Judith K.; Neumark, David; and Troske, Kenneth R. "Why Are Racial and Ethnic Wage Gaps Larger for Men than for Women? Exploring the Role of Segregation Using the New Worker-Establishment Characteristics Database." In The Creation and Analysis of EmployerEmployee Matched Data, edited by John Haltiwanger, Julia Lane, James Spletzer, Jules Theeuwes, and Kenneth Troske, pp. 175-204. Amsterdam: Elsevier Science, 1999.

Boozer, Michael A.; Krueger, Alan B.; and Wolkon, Shari. "Race and School Quality Since Brown v. Board of Education." Brookings Papers on Economic Activity: Microeconomics (1992): 269-326

Bound, John, and Krueger, Alan B. "The Extent of Measurement Error in Longitudinal Earnings Data: Do Two Wrongs Make a Right?” Journal of Labor Economics 9 (January 1991): 1-24.

Card, David, and Krueger, Alan B. "School Quality and Black-White Relative Earnings: A Direct Assessment." Quarterly Journal of Economics 107 (February 1992): 151-200.

Card, David, and Lemieux, Thomas. "Wage Dispersion, Returns to Skill, and Black-White Wage Differentials." Journal of Econometrics 74 (October 1996): 319-61.

."Can Falling Supply Explain the Rising Return to College for Younger Men? A Cohort-Based Analysis." Quarterly Journal of Economics 116 (May 2001): 705-46.

Carrington, William J., and Troske, Kenneth R. "Interfirm Segregation and the Black/White Wage Gap." Journal of Labor Economics 16 (April 1998): 231-60.

Cook, Michael D., and Evans, William N. "Families or Schools? Explaining the Convergence in White and Black Academic Performance.” Journal of Labor Economics 18 (October 2000): 729-54.

Darity, William A., Jr., and Mason, Patrick L. "Evidence on Discrimination in Employment: Codes of Color, Codes of Gender.” Journal of Economic Perspectives 12 (Spring 1998): 63-90.

Dickens, William T., and Ross, Brian A. "Consistent Estimation Using Data from More than One Sample." NBER Technical Working Paper 33, 1984.

DiNardo, John E., and Pischke, Jörn-Steffen. "The Returns to Computer Use Revisited: Have Pencils Changed the Wage Structure Too?” Quarterly Journal of Economics 112 (February 1997): 291-303.

England, Paula, and Kilbourne, Barbara. Occupational Measures from the Dictionary of Occupational Titles for 1980 Census Detailed Occupations. Ann Arbor, Mich.: Inter-university Consortium for Political and Social Research, ICPSR \#8942, Fall 1988.

Filer, Randall K. "The Role of Personality and Taste in Determining Occupational Structure." Industrial and Labor Relations Review 39 (April 1986): 412-24.

Gibbons, Robert, and Katz, Lawrence. "Does Unmeasured Ability Explain Inter-Industry Wage Differentials?" Review of Economic Studies 59 (July 1992): 515-35. 
Gill, Andrew M. "The Role of Discrimination in Determining Occupational Structure." Industrial and Labor Relations Review 42 (July 1989): 610-23.

Grogger, Jeff. "Does School Quality Explain the Recent Black/White Wage Trend?" Journal of Labor Economics 14 (April 1996): 231-53.

Hirsch, Barry T., and Macpherson, David A. "Wages, Racial Composition, and Quality Sorting in Labor Markets." Social Science Research Network Working Paper, June 2001 (available at www.ssrn.com).

. Union Membership and Earnings Data Book: Compilations from the Current Population Survey. Washington D.C.: The Bureau of National Affairs, 2002.

Hirsch, Barry T., and Schumacher, Edward J. "Labor Earnings, Discrimination, and the Racial Composition of Jobs," Journal of Human Resources, 27 (Fall 1992): 602-28.

Hwang, Hae-shin; Reed, Robert W.; and Hubbard, Carlton. "Compensating Wage Differentials and Unobserved Productivity.” Journal of Political Economy 100 (August 1992): 835-58.

Johnson, William R. “A Theory of Job Shopping.” Quarterly Journal of Economics 97 (May 1978): 261-78.

Jovanovic, Boyan. "Job Matching and the Theory of Turnover." Journal of Political Economy 87 (October 1979): 972-90.

Macpherson, David A., and Hirsch, Barry T. "Wages and Gender Composition: Why Do Women's Jobs Pay Less?" Journal of Labor Economics 13 (July 1995): 426-71.

Mason, Patrick L. "Male Interracial Wage Differentials: Competing Explanations." Cambridge Journal of Economics 23 (May 1999): 261-99.

Mellow, Wesley, and Sider, Hal. "Accuracy of Response in Labor Market Surveys: Evidence and Implications." Journal of Labor Economics 1 (October 1983): 331-44.

Moulton, Brent R. "An Illustration of a Pitfall in Estimating the Effects of Aggregate Variables on Micro Units." Review of Economics and Statistics 72 (May 1990): 334-38.

Neal, Derek A., and Johnson, William R. "The Role of Premarket Factors in Black-White Wage Differences.” Journal of Political Economy 104 (October 1996): 869-95.

O’Neill, June. "The Role of Human Capital in Earnings Differences Between Black and White Men." Journal of Economic Perspectives 4 (Fall 1990): 25-45.

Pierce, Brooks. "Job Content As Ability.” Bureau of Labor Statistics, unpublished paper, November 2000.

Rivera-Batiz, Francisco L. "Quantitative Literacy and the Likelihood of Employment Among Young Adults." Journal of Human Resources 27 (Spring 1992): 313-28.

Silber, Jacques G. "On the Measurement of Employment Segregation." Economics Letters 30 (September 1989): 237-43.

Sorensen, Elaine. "Measuring the Effect of Occupational Sex and Race Composition on Earnings." In Pay Equity: Empirical Inquiries, edited by R.T. Michael, H.I. Hartmann, and B. O'Farrell, pp. 49-69. Washington, D.C.: National Academy Press, 1989. 
Table 1: Racial Composition and Occupational Segregation, 1973-1998

\begin{tabular}{|c|c|c|c|c|c|c|c|c|c|c|}
\hline \multirow[b]{3}{*}{ Year } & \multicolumn{5}{|c|}{ Males } & \multicolumn{5}{|c|}{ Females } \\
\hline & \multicolumn{2}{|c|}{ Sample Size } & \multicolumn{2}{|c|}{ B } & \multicolumn{3}{|c|}{ Sample Size } & \multicolumn{2}{|c|}{$\overline{\mathrm{B}}$} & \\
\hline & Black & White & Black & White & $\begin{array}{l}\text { Duncan } \\
\text { Index }\end{array}$ & Black & White & Black & White & $\begin{array}{c}\text { Duncan } \\
\text { Index }\end{array}$ \\
\hline 1973 & 1,786 & 20,154 & .157 & .087 & .384 & 1,673 & 13,570 & .210 & .099 & .374 \\
\hline 1978 & 1,817 & 21,255 & .145 & .090 & .344 & 1,897 & 16,145 & .186 & .099 & .358 \\
\hline 1983 & 7,051 & 79,915 & .138 & .091 & .316 & 7,909 & 67,092 & .159 & .102 & .300 \\
\hline 1988 & 7,148 & 75,390 & .143 & .099 & .298 & 8,601 & 67,047 & .161 & .111 & .284 \\
\hline 1993 & 7,004 & 73,127 & .142 & .101 & .293 & 8,654 & 68,600 & .151 & .110 & .268 \\
\hline 1998 & 6,107 & 64,751 & .148 & .108 & .284 & 8,020 & 59,772 & .161 & .123 & .241 \\
\hline
\end{tabular}

Calculations are from the 1973 and 1978 May CPS and the 1983, 1988, 1993, and 1998 CPS-ORG monthly earnings files. $\bar{B}$ measures the proportion of black to total employment in workers' detailed occupation. The Duncan segregation index is calculated annually by $\left|\mathrm{w}_{\mathrm{j}}-\mathrm{b}_{\mathrm{j}}\right|$, where $\mathrm{w}$ and $\mathrm{b}$ are the proportions of nonblack and black employment in occupation $\mathrm{j}$. 
Table 2: Means of Selected Individual and Occupational Variables by Race and Racial Composition Category

\begin{tabular}{|c|c|c|c|c|c|c|}
\hline & \multicolumn{3}{|c|}{$\begin{array}{l}\text { Black Means } \\
\text { Value of B }\end{array}$} & \multicolumn{3}{|c|}{$\begin{array}{l}\text { White Means } \\
\text { Value of B }\end{array}$} \\
\hline & $0-.09$ & $.09-.16$ & $.16+$ & $0-.09$ & $.09-.16$ & $.16+$ \\
\hline \multicolumn{7}{|l|}{ Males: } \\
\hline Wage (1998 \$) & 15.252 & 12.359 & 10.425 & 19.328 & 14.076 & 11.126 \\
\hline \%H.S. Dropout & 0.114 & 0.172 & 0.212 & 0.076 & 0.151 & 0.226 \\
\hline$\%$ College Grad & 0.306 & 0.142 & 0.064 & 0.397 & 0.189 & 0.083 \\
\hline OCC-Training & 0.456 & 0.347 & 0.249 & 0.472 & 0.373 & 0.243 \\
\hline OCC-Computer & 0.498 & 0.334 & 0.175 & 0.535 & 0.353 & 0.181 \\
\hline DOT-Numerical & 3.095 & 2.554 & 2.289 & 3.184 & 2.599 & 2.297 \\
\hline DOT-Verbal & 3.369 & 2.794 & 2.466 & 3.461 & 2.848 & 2.454 \\
\hline DOT-Spatial & 2.870 & 2.597 & 2.384 & 2.895 & 2.632 & 2.382 \\
\hline DOT-Environment & 0.622 & 0.685 & 0.776 & 0.555 & 0.695 & 0.782 \\
\hline DOT-Physical & 1.776 & 1.994 & 2.063 & 1.662 & 1.984 & 2.063 \\
\hline DOT-Strength & 2.264 & 2.586 & 2.860 & 2.186 & 2.565 & 2.866 \\
\hline OCC-\%Female & 0.286 & 0.298 & 0.348 & 0.276 & 0.284 & 0.339 \\
\hline OCC-\%Hispanic & 0.084 & 0.116 & 0.147 & 0.076 & 0.113 & 0.150 \\
\hline $\mathrm{N}$ & 12,104 & 17,034 & 15,957 & 262,179 & 163,738 & 82,869 \\
\hline \multicolumn{7}{|l|}{ Females: } \\
\hline Wage (1998 \$) & 14.022 & 11.198 & 9.117 & 14.402 & 11.387 & 9.274 \\
\hline$\%$ H.S. Dropout & 0.041 & 0.095 & 0.219 & 0.039 & 0.084 & 0.207 \\
\hline$\%$ College Grad & 0.337 & 0.206 & 0.061 & 0.345 & 0.264 & 0.092 \\
\hline OCC-Training & 0.490 & 0.416 & 0.307 & 0.477 & 0.425 & 0.296 \\
\hline OCC-Computer & 0.689 & 0.509 & 0.234 & 0.663 & 0.517 & 0.260 \\
\hline DOT-Numerical & 3.205 & 2.807 & 2.266 & 3.172 & 2.819 & 2.291 \\
\hline DOT-Verbal & 3.699 & 3.182 & 2.586 & 3.651 & 3.217 & 2.616 \\
\hline DOT-Spatial & 2.446 & 2.255 & 2.243 & 2.452 & 2.255 & 2.266 \\
\hline DOT-Environment & 0.128 & 0.228 & 0.622 & 0.128 & 0.202 & 0.535 \\
\hline DOT-Physical & 1.317 & 1.347 & 2.047 & 1.311 & 1.313 & 1.980 \\
\hline DOT-Strength & 1.730 & 1.986 & 2.532 & 1.755 & 1.961 & 2.456 \\
\hline OCC-\%Female & 0.653 & 0.687 & 0.682 & 0.651 & 0.705 & 0.674 \\
\hline OCC-\%Hispanic & 0.060 & 0.096 & 0.138 & 0.061 & 0.092 & 0.140 \\
\hline $\mathrm{N}$ & 14,196 & 20,902 & 22,845 & 210,329 & 169,561 & 91,934 \\
\hline
\end{tabular}

All means are calculated across individuals in the 1992-98 CPS-ORG. B is the proportion of black to total employment in workers' detailed occupation. Wage is usual weekly earnings divided by usual weekly hours, in 1998 dollars. \%H.S. Dropout measures the proportion without high school degree and \%College Grad the proportion with 4-year college degree or more. Variables preceded by "OCC" and "DOT" are means in workers' occupation and are fixed over the 1992-98 period. OCC-Training is the proportion of workers receiving formal or informal training on the current job, calculated from the January 1983 and 1991 CPS supplements. OCC-Computer is the proportion using computers at their job, calculated as the three-year average based on October 1989, 1993, and 1997 CPS supplements. DOT measures are taken from the Dictionary of Occupational Titles and matched to workers based on Census of Population occupation codes: DOT-Numerical, DOT-Verbal, and DOT-Spatial are a 1-5 index of required aptitude levels for the occupation (rescaled from low to high), DOTEnvironment is the number of work environment disamenities (including hazards) from 0-6, DOT-Physical is the number of physical demands from $0-4$, and DOT-Strength is measured by a 1-5 index from low to high strength required. OCC-\%Female and OCC-\%Hispanic are the proportions of these worker groups in total employment for detailed occupations over 1992-98. 
Table 3: Panel Data Estimates of $\ln B$ and $\triangle \ln B$ Coefficients for Wage Level and Wage Change Models Using the CPS-ORG, March CPS, and CPS Displaced Worker Surveys

$\frac{\text { Black Males }}{\text { Standard Expanded }} \frac{\text { White Males }}{\text { Standard Expanded }} \frac{\text { Black Females }}{\text { Standard Expanded }} \frac{\text { White Females }}{\text { Standard Expanded }}$

CPS-ORG Panel, 1991/92-1997/98:

\begin{tabular}{lll|ll|ll|ll} 
Levels & -0.1656 & -0.0307 & -0.1733 & -0.0456 & -0.1697 & -0.0834 & -0.1628 & -0.0435 \\
& $(0.0088)$ & $(0.0137)$ & $(0.0023)$ & $(0.0033)$ & $(0.0077)$ & $(0.0129)$ & $(0.0026)$ & $(0.0038)$ \\
Change & & & & & & & & \\
& -0.0635 & -0.0177 & -0.0516 & -0.0205 & -0.0559 & -0.0038 & -0.0425 & -0.0093 \\
& $(0.0169)$ & $(0.0209)$ & $(0.0041)$ & $(0.0048)$ & $(0.0153)$ & $(0.0191)$ & $(0.0047)$ & $(0.0056)$
\end{tabular}

$\mathrm{N}$

11,009

128,052

15,004

122,900

March CPS Retrospective Panel, 1992-98:

\begin{tabular}{lll|ll|ll|lr} 
Levels & -0.1592 & -0.0372 & -0.1746 & -0.0498 & -0.1564 & -0.0397 & -0.1614 & -0.0503 \\
& $(0.0148)$ & $(0.0219)$ & $(0.0040)$ & $(0.0054)$ & $(0.0122)$ & $(0.0199)$ & $(0.0044)$ & $(0.0063)$ \\
Change & & & & & & & & \\
& -0.0495 & -0.0152 & -0.0676 & -0.0392 & 0.0237 & 0.0087 & -0.0465 & -0.0421 \\
& $(0.0388)$ & $(0.0462)$ & $(0.0105)$ & $(0.0129)$ & $(0.0325)$ & $(0.0439)$ & $(0.0113)$ & $(0.0142)$ \\
$\mathrm{N}$ & \multicolumn{2}{c}{4,152} & \multicolumn{2}{c}{45,523} & \multicolumn{2}{c}{5,501} & & 43,583
\end{tabular}

CPS DWS, 1984-98, Plant Closing and Layoff Sample:

\begin{tabular}{llr|ll|ll|ll} 
Levels & -0.1360 & -0.0190 & -0.1552 & -0.0132 & -0.0775 & 0.0867 & -0.1722 & -0.0495 \\
& $(0.0370)$ & $(0.0518)$ & $(0.0090)$ & $(0.0119)$ & $(0.0420)$ & $(0.0607)$ & $(0.0126)$ & $(0.0168)$ \\
Change & & & & & & & & \\
& -0.0315 & 0.0346 & -0.0241 & -0.0024 & -0.0094 & 0.0344 & -0.0566 & -0.0136 \\
& $(0.0358)$ & $(0.0484)$ & $(0.0080)$ & $(0.0102)$ & $(0.0357)$ & $(0.0473)$ & $(0.0114)$ & $(0.0150)$
\end{tabular}

$\mathrm{N}$

631

8,476

623

5,840

Dependent variables are $\operatorname{lnW}$ in level equations and $\Delta \operatorname{lnW}$ in change equations. Coefficients (standard errors) on $\ln B$ and $\Delta \operatorname{lnB}$ are shown. The ORG "Standard" specification includes variables measured at the individual level: potential experience and its square and dummies for educational degree and schooling level (12), union membership, part-time, marital status (2), public sector (3), region (8), large metropolitan area, industry (13), and year (6). The "Expanded" specification adds variables measuring occupational means of the individual $X$ 's, plus occupational variables defined in Table 2: \%H.S. Dropout, \%College Grad, OCC-Training, OCC-Computer, DOT-Numerical, DOT-Verbal, DOTSpatial, DOT-Environment, DOT-Physical, DOT-Strength, OCC-\%Female, and OCC-\%Hispanic. Industry level variable IND-Big Firm is also included, measuring the proportion in the worker's industry in firms with $>1000$ employees, calculated from the March 1992-98 CPS files. The ORG panel presents the coefficient on $\Delta \operatorname{lnB}$ interacted with industry/occupation changer; dummies for ind/occ, ind-only, and occ-only change are included. Change equations from the March CPS files differ in specification from the ORG by the inclusion of change in region (fixed in ORG panels), and the inclusion of changes in marital status and union status at the aggregate rather than individual level. The DWS results are based on the January 1984, 1986, 1988, 1990, 1992 and February 1994, 1996, and 1998 CPS supplemental Displaced Worker Surveys. The sample consists of workers who were age 20 and older and who were displaced from a private-sector job because of a plant closing, slack work, or a position of shift that was eliminated. The dependent variable in the change equation is the difference between the log of current weekly earnings and the log of pre-displacement weekly earnings. The DWS change models include the same variables included in the March CPS, plus dummies for year of displacement and survey year. 


\section{IZA Discussion Papers}

\begin{tabular}{|c|c|c|c|c|}
\hline No. & Author(s) & Title & Area & Date \\
\hline 726 & S. Habermalz & $\begin{array}{l}\text { Job Matching and the Returns to Educational } \\
\text { Signals }\end{array}$ & 1 & $02 / 03$ \\
\hline 727 & $\begin{array}{l}\text { M. Raiser } \\
\text { M. Schaffer } \\
\text { J. Schuchardt }\end{array}$ & Benchmarking Structural Change in Transition & 4 & $02 / 03$ \\
\hline 728 & $\begin{array}{l}\text { M. Lechner } \\
\text { J. A. Smith }\end{array}$ & What is the Value Added by Caseworkers? & 6 & $02 / 03$ \\
\hline 729 & $\begin{array}{l}\text { A. Voicu } \\
\text { H. Buddelmeyer }\end{array}$ & $\begin{array}{l}\text { Children and Women's Participation Dynamics: } \\
\text { Transitory and Long-Term Effects }\end{array}$ & 3 & $02 / 03$ \\
\hline 730 & $\begin{array}{l}\text { M. Piva } \\
\text { M. Vivarelli }\end{array}$ & $\begin{array}{l}\text { Innovation and Employment: Evidence from } \\
\text { Italian Microdata }\end{array}$ & 2 & $02 / 03$ \\
\hline 731 & $\begin{array}{l}\text { B. R. Chiswick } \\
\text { N. DebBurman }\end{array}$ & $\begin{array}{l}\text { Educational Attainment: Analysis by Immigrant } \\
\text { Generation }\end{array}$ & 1 & $02 / 03$ \\
\hline 732 & $\begin{array}{l}\text { A. Frank } \\
\text { A. Ichino }\end{array}$ & Clean Evidence on Peer Pressure & 5 & $03 / 03$ \\
\hline 733 & $\begin{array}{l}\text { S. Wolter } \\
\text { S. Denzler }\end{array}$ & $\begin{array}{l}\text { Wage Elasticity of the Teacher Supply in } \\
\text { Switzerland }\end{array}$ & 2 & $03 / 03$ \\
\hline 734 & S. Wolter & Sibling Rivalry: A Six Country Comparison & 2 & $03 / 03$ \\
\hline 735 & $\begin{array}{l}\text { R. Desmet } \\
\text { A. Jousten } \\
\text { S. Perelman } \\
\text { P. Pestieau }\end{array}$ & $\begin{array}{l}\text { Micro-Simulation of Social Security Reforms in } \\
\text { Belgium }\end{array}$ & 3 & $03 / 03$ \\
\hline 736 & $\begin{array}{l}\text { I. Bolvig } \\
\text { P. Jensen } \\
\text { M. Rosholm }\end{array}$ & The Employment Effects of Active Social Policy & 6 & $03 / 03$ \\
\hline 737 & $\begin{array}{l}\text { A. L. Booth } \\
\text { M. Francesconi } \\
\text { G. Zoega }\end{array}$ & $\begin{array}{l}\text { Unions, Work-Related Training, and Wages: } \\
\text { Evidence for British Men }\end{array}$ & 3 & $03 / 03$ \\
\hline 738 & V. Grossmann & $\begin{array}{l}\text { Managerial Job Assignment and Imperfect } \\
\text { Competition in Asymmetric Equilibrium }\end{array}$ & 1 & 03/03 \\
\hline 739 & M. Fertig & $\begin{array}{l}\text { Who's to Blame? The Determinants of German } \\
\text { Students' Achievement in the PISA } 2000 \text { Study }\end{array}$ & 1 & $03 / 03$ \\
\hline 740 & $\begin{array}{l}\text { B. T. Hirsch } \\
\text { S. L. Mehay }\end{array}$ & $\begin{array}{l}\text { Evaluating the Labor Market Performance of } \\
\text { Veterans Using a Matched Comparison Group } \\
\text { Design }\end{array}$ & 6 & $03 / 03$ \\
\hline 741 & $\begin{array}{l}\text { B. T. Hirsch } \\
\text { D. A. Macpherson }\end{array}$ & $\begin{array}{l}\text { Wages, Sorting on Skill, and the Racial } \\
\text { Composition of Jobs }\end{array}$ & 5 & $03 / 03$ \\
\hline
\end{tabular}

An updated list of IZA Discussion Papers is available on the center's homepage www.iza.org. 